\title{
NUMERICAL SOLUTION OF THE BARENBLATT - ZHELTOV - KOCHINA EQUATION WITH ADDITIVE "WHITE NOISE" IN SPACES OF DIFFERENTIAL FORMS ON A TORUS
}

D. E. Shafranov, South Ural State University, Chelyabinsk, Russian Federation, shafranovde@susu.ru

The paper is devoted to the search for numerical solutions to the Cauchy problem for the linear stochastic Barenblatt - Zheltov - Kochina equation in space of smooth differential forms on a torus. Based on the previously obtained results on the type of analytical solution to the stochastic version of the Barenblatt - Zheltov - Kochina equation in spaces of smooth differential forms on smooth compact Riemannian manifolds without boundary, we choose several terms from the analytical solution in order to construct graphs of the numerical solution for various values of the coefficients and the inhomogeneous term. Since these equations are Sobolev type equations with a degenerate operator at the derivative, we can solve various initial-boundary value problems using the theory of degenerate analytic groups and semigroups of resolving operators. In the deterministic case, the solution is based on the phase subspace of the original space. In spaces of differential forms, we use the invariant form of the Laplacian, i.e. the Laplace - Beltrami operator. The phase space method is also used in non-deterministic case, but we use the Nelson - Gliklikh derivative due to the non-differentiability of "white noise" in the usual sense. In this paper, a two-dimensional torus plays the role of a smooth compact oriented Riemannian manifold without boundary. Numerical solutions are found using the Galerkin method and are presented for several fixed time points as graphs of the coefficients of differential forms obtained in Maple.

Keywords: Sobolev type equation; Nelson-Gliklikh derivative; Laplace-Beltrami operator.

\section{Introduction}

In its initial statement [1], the Barenblatt - Zheltov - Kochina equation

$$
(\lambda-\Delta) u_{t}=\alpha \Delta u+f
$$

simulates the pressure of a viscoelastic fluid filtered in a fractured porous medium. There exist other physical interpretations of this equation [2], [3]. Different types (including cases of different functional spaces) of initial boundary value problems for this equation were solved by reducing to abstract Sobolev type equations (with noninvertible operator at derivative) [4]

$$
L \dot{u}=M u+f .
$$

In turn, the abstract Sobolev type equation with operators $L, M \in \mathcal{L}(\mathfrak{U} ; \mathfrak{U})$ is reduced to the equivalent system on splitting spaces

$$
\mathfrak{U}=\mathfrak{U}^{0} \oplus \mathfrak{U}^{1} ; \mathfrak{F}=\mathfrak{F}^{0} \oplus \mathfrak{F}^{1} .
$$

by the phase space method proposed by G. A. Sviridyuk. Recently, in the Chelyabinsk scientific school of Sobolev type equations, various results were obtained for the 
Barenblatt - Zheltov - Kochina equation, in particular, in spaces of differential forms defined on a Riemannian manifold without boundary [5], [6], and, for the stochastic version [15], [16] of this equation, in the space of differential $K$-"noises" [7], [8]. Note that in this case we use the invariant generalization of the Laplace operator in spaces of differential forms, i.e. the Laplace - Beltrami operator [9], and differentiability of, generally speaking, just continuous stochastic processes in the sense of Nelson - Gliklikh [10], which is extended to the Sobolev type equations [11].

The actual problem is to find numerical solutions to Sobolev type equations [17]. The aim of this paper is to obtain and analyze a numerical solution to the Cauchy problem

$$
u(0)=u_{0}
$$

for equation (1) on a two-dimensional torus, which we use as an example of a Riemannian manifold. To this end, we use a numerical algorithm based on the Galerkin approximation method in order to carry out computational experiments for some set of initial parameters of the Barenblatt - Zheltov - Kochina equation in Maple. The results are presented in the form of sets of time-fixed values of the coefficients of differential forms.

The paper consists of Introduction, three sections, Conclusion, and References. Section 1 contains preliminary information and describes spaces of differential $K$ - "noises" [7], [8]. Section 2 describes an example for the Barenblatt - Zheltov - Kochina equation on a torus. In Section 3, we use the Galerkin approximation method in order to construct a numerical solution to the Cauchy problem. References do not pretend to be complete, but only meet the preferences of the author.

\section{Sobolev Type Equations in the Deterministic Case and Differential K-"Noises" on Differential Form Spaces}

Let $\mathfrak{U}$ and $\mathfrak{F}$ be Banach spaces, and the operators $L, M \in \mathcal{L}(\mathfrak{U} ; \mathfrak{F})$ (i.e., the operators are linear and continuous). Consider the $L$-resolvent set $\rho^{L}(M)=$ $\left\{\mu \in \mathbb{C}:(\mu L-M)^{-1} \in \mathcal{L}(\mathfrak{F} ; \mathfrak{U})\right\}$ and $L$-spectrum $\sigma^{L}(M)=\mathbb{C} \backslash \rho^{L}(M)$ of the operator $M$. If $L$-spectrum $\sigma^{L}(M)$ of the operator $M$ is bounded, then the operator $M$ is called $(L, \sigma)$-bounded. If the operator $M$ is $(L, \sigma)$-bounded, then there exist the projectors

$$
P=\frac{1}{2 \pi i} \int_{\gamma} R_{\mu}^{L}(M) d \mu \in \mathcal{L}(\mathfrak{U}), \quad Q=\frac{1}{2 \pi i} \int_{\gamma} L_{\mu}^{L}(M) d \mu \in \mathcal{L}(\mathfrak{F}) .
$$

Here $R_{\mu}^{L}(M)=(\mu L-M)^{-1} L$ and $L_{\mu}^{L}(M)=L(\mu L-M)^{-1}$ are the right and the left $L$-resolvents of the operator $M$, respectively, and the closed contour $\gamma \subset \mathbb{C}$ bounds the domain containing $\sigma^{L}(M)$. Set $\mathfrak{U}^{0}\left(\mathfrak{U}^{1}\right)=\operatorname{ker} P(\operatorname{im} P)$, $\mathfrak{F}^{0}\left(\mathfrak{F}^{1}\right)=\operatorname{ker} Q(\operatorname{im} Q)$ and denote by $L_{k}\left(M_{k}\right)$ the restriction of the operator $L(M)$ on $\mathfrak{U}^{k}, k=0,1$.

Theorem 1. [4] (Sviridyuk's splitting theorem)

Let the operator $M$ be $(L, \sigma)$-bounded. Then

(i) the operators $L_{k}\left(M_{k}\right) \in \mathcal{L}\left(\mathfrak{U}^{k} ; \mathfrak{F}^{k}\right), k=0,1$;

(ii) there exist the operators $M_{0}^{-1} \in \mathcal{L}\left(\mathfrak{F}^{0} ; \mathfrak{U}^{0}\right)$ and $L_{1}^{-1} \in \mathcal{L}\left(\mathfrak{F}^{1} ; \mathfrak{U}^{1}\right)$. 
Construct the operators $H=M_{0}^{-1} L_{0} \in \mathcal{L}\left(\mathfrak{U}^{0}\right), S=L_{1}^{-1} M_{1} \in \mathcal{L}\left(\mathfrak{U}^{1}\right)$. Under the conditions of the theorem,

$$
(\mu L-M)^{-1}=-\sum_{k=0}^{\infty} \mu^{k} H^{k} M_{0}^{-1}(\mathbb{I}-Q)+\sum_{k=1}^{\infty} \mu^{-k} S^{k-1} L_{1}^{-1} Q
$$

for all $\mu \in \rho^{L}(M)$. The operator $M$ is called $(L, p)$-bounded, $p \in\{0\} \cup \mathbb{N}$, if $\infty$ is a removable singular point (i.e. $H \equiv \mathbb{O}, p=0$ ) or a pole of the order $p \in \mathbb{N}$ (i.e. $H^{p} \neq \mathbb{O}$, $\left.H^{p+1} \equiv \mathbb{O}\right)$ of $L$-resolvents $(\mu L-M)^{-1}$ of the operator $M$.

A vector function $u \in C^{\infty}(\mathbb{R} ; \mathfrak{U})$ is a solution to equation (1), if $u$ satisfies the equation on $\mathbb{R}$. A solution $u$ to equation (1) is a solution to problem (1), (3), if $u$ satisfies condition $(3)$.

Theorem 2. [4] For the $(L, p)$-bounded operator $M, p \in\{0\} \cup \mathbb{N}$ and for any initial $u_{0} \in \mathfrak{P} \subset \mathfrak{U}^{1}$ and $f \in C^{\infty}(\mathbb{R} ; \mathfrak{U})$, for problem (1),(3) there exist analytic resolving groups of operators of the form

$$
U^{t}=\frac{1}{2 \pi i} \int_{\gamma} R_{\mu}^{L}(M) e^{\mu t} d \mu \in \mathcal{L}(\mathfrak{U}), F^{t}=\frac{1}{2 \pi i} \int_{\gamma} L_{\mu}^{L}(M) e^{\mu t} d \mu \in \mathcal{L}(\mathfrak{F}),
$$

and the solution has the form

$$
u(t)=U^{t} u_{0}+-\sum_{q=0}^{p} H^{p} M_{0}^{-1} \frac{d^{q}(I-Q) f}{d t^{q}}(t)+\int_{0}^{t} U^{t-s} Q f d s .
$$

Let $\Omega \equiv(\Omega, \mathcal{S}, \mathbf{P})$ be a complete probability space with the probability measure $\mathbf{P}$ associated with the $\sigma$-algebra $\mathcal{S}$ of subsets of the set $\Omega$. Denote by $\mathbb{R}$ the set of real numbers endowed with the structure of $\sigma$-algebra. Then the mapping $\chi: \mathcal{S} \rightarrow \mathbb{R}$ is called a random variable. The set of random variables $\{\chi\}$ with zero mathematical expectation $(\mathbf{E} \chi=0)$ and finite dispersion $(\mathbf{D} \chi<+\infty)$ forms the Hilbert space $\mathbf{L}_{\mathbf{2}}$ with the scalar product $\left(\chi_{1}, \chi_{2}\right)=\mathbf{E} \chi_{1} \chi_{2}$ and the norm $\|\chi\|_{\mathbf{L}_{2}}$. Let $\mathcal{S}_{0}$ be a $\sigma$-subalgebra of the $\sigma$-algebra $\mathcal{S}$. Construct the subspace $\mathbf{L}_{2}^{0} \subset \mathbf{L}_{2}$ of random variables measurable with respect to $\mathcal{S}_{0}$. Denote by $\Pi: \mathbf{L}_{\mathbf{2}} \rightarrow \mathbf{L}_{\mathbf{2}}^{\mathbf{0}}$ the orthoprojector. Consider the random variable $\chi \in \mathbf{L}_{\mathbf{2}}$, then $\Pi \chi$ is called a conditional expectation and is denoted by $\mathbf{E}\left(\chi \mid \mathcal{S}_{0}\right)$.

For some interval $\mathfrak{I} \subset \mathbb{R}$, the measurable mapping $\eta: \mathfrak{I} \times \mathcal{S} \rightarrow \mathbb{R}$ is called a stochastic process, and the random variable $\eta(\cdot, \omega)$ is called a section of the stochastic process, and the function $\eta(t, \cdot), t \in \mathfrak{I}$ is called a trajectory of the stochastic process. The stochastic process $\eta=\eta(t, \cdot)$ is called continuous, if a.s. (almost sure), i.e. for a.a. (almost all) $\omega \in \mathcal{S}$, the trajectories $\eta(t, \omega)$ are continuous functions. The set $\{\eta=\eta(t, \omega)\}$ of all continuous stochastic processes with values in $\mathbf{L}_{\mathbf{2}}$ forms the Banach space $\mathbf{C L}_{2}$ with the norm

$$
\|\eta\|_{\mathbf{C L}_{2}}=\sup _{t \in \mathfrak{I}}(\mathbf{D} \eta(t, \omega))^{1 / 2} .
$$

Fix an arbitrary stochastic process $\eta \in \mathbf{C L}_{\mathbf{2}}$.

Definition 1. A random variable

$$
\stackrel{\circ}{\eta}(\cdot, \omega)=\frac{1}{2}\left(\lim _{\Delta t \rightarrow 0+} \mathbf{E}_{t}^{\eta}\left(\frac{\eta(t+\Delta t, \cdot)-\eta(t, \cdot)}{\Delta t}\right)+\lim _{\Delta t \rightarrow 0+} \mathbf{E}_{t}^{\eta}\left(\frac{\eta(t, \cdot)-\eta(t-\Delta t, \cdot)}{\Delta t}\right)\right)
$$


is called the Nelson - Gliklikh derivative of the stochastic process $\eta$ at the point $t \in \mathfrak{I}$, if the limit exists in the sense of a uniform metric on $\mathbb{R}$.

Here $\mathbf{E}_{t}^{\eta}=\mathbf{E}\left(\cdot \mid \mathcal{N}_{t}^{\eta}\right)$, and $\mathcal{N}_{t}^{\eta} \subset \mathcal{S}$ is a $\sigma$-algebra generated by the random variable $\eta(t, \omega)$.

If the Nelson - Gliklikh derivatives $\stackrel{\circ}{\eta}(\cdot, \omega)$ of the stochastic process $\eta(\cdot, \omega)$ there exist for a.a. points of the interval $\mathfrak{I}$, then there exists the Nelson - Gliklikh derivative $\stackrel{\circ}{\eta}(\cdot, \omega)$ on the interval $\mathfrak{I}$ (a.s. on $\mathfrak{I}$ ). Denote the set of continuous stochastic processes with continuous

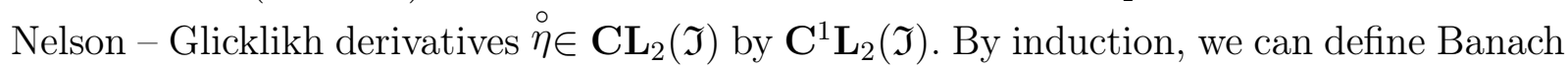
spaces $\mathbf{C}^{l} \mathbf{L}_{2}(\mathfrak{I}), l \in \mathbb{N}$, of the stochastic processes having continuous Nelson - Glicklikh derivatives on $\mathfrak{I}$ up to the order $l \in \mathbb{N}$ inclusively.

The norms of these spaces have the form

$$
\|\eta\|_{\mathbf{C}^{l} \mathbf{L}_{2}}=\sup _{t \in \mathfrak{I}}\left(\sum_{k=0}^{l} \mathbf{D} \stackrel{\circ}{\eta}^{l}(t, \omega)\right)^{1 / 2}
$$

where $\eta^{0} \equiv \eta$. Since "white noise" belongs to all the spaces $\mathbf{C}^{l} \mathbf{L}_{2}\left(\mathbb{R}_{+}\right), l \in\{0\} \cup \mathbb{N}$, then these spaces are called the spaces of "noises".

We also use the spaces of random $\mathbf{K}$-variables. Let space $\mathfrak{H}$ be a separable Hilbert space with an orthonormal basis $\left\{\varphi_{k}\right\}$, a monotone sequence $\mathbf{K}=\left\{\lambda_{k}\right\} \subset \mathbb{R}_{+}\left(\sum_{k=1}^{\infty} \lambda_{k}^{2}<+\infty\right)$, and a sequence $\left\{\xi_{k}\right\}=\xi_{k}(\omega) \subset \mathbf{L}_{2}$ of random variables with norm $\left\|\xi_{k}\right\|_{\mathbf{L}_{2}} \leq C$ for one $C \in \mathbb{R}_{+}$and for all $k \in \mathbb{N}$. We define a $\mathfrak{H}$-valued random $\mathbf{K}$-variable $\xi(\omega)=\sum_{k=1}^{\infty} \lambda_{k} \xi_{k}(\omega) \varphi_{k}$. Complete the linear span of the set $\left\{\lambda_{k} \xi_{k} \varphi_{k}\right\}$ with the norm

$$
\|\eta\|_{\mathbf{H}_{\mathbf{K}} \mathbf{L}_{2}}^{2}=\left(\sum_{k=1}^{\infty} \lambda_{k}^{2} \mathbf{D} \xi_{k}\right)^{1 / 2}
$$

and call the result by a space of ( $\mathfrak{H}$-valued) random $\mathbf{K}$-variables. Denote the space by $\mathbf{H}_{\mathbf{K}} \mathbf{L}_{2}$. The obtained space $\mathbf{H}_{\mathbf{K}} \mathbf{L}_{2}$ is a Hilbert space and contains a random $\mathbf{K}$-variable $\xi=\xi(\omega) \in \mathbf{H}_{\mathbf{K}} \mathbf{L}_{2}$. Similar, a Banach space of ( $\mathfrak{H}$-valued) $\mathbf{K}$-"noises" is defined as a completion of the linear span of the set $\left\{\lambda_{k} \xi_{k} \varphi_{k}\right\}$ with the norm

$$
\|\eta\|_{\mathbf{C}^{l} \mathbf{H}_{\mathbf{K}} \mathbf{L}_{2}}^{2}=\sup _{t \in \mathfrak{I}}\left(\sum_{k=1}^{\infty} \lambda_{k}^{2} \sum_{m=1}^{l} \mathbf{D} \stackrel{\circ}{\eta_{k}^{m}}\right)^{1 / 2}
$$

where a sequence $\left\{\eta_{k}\right\} \subset \mathbf{C}^{l} \mathbf{L}_{2}, l \in\{0\} \cup \mathbb{N}$. The vector $\eta(t, \omega)=\sum_{k=1}^{\infty} \lambda_{k} \eta_{k}(t, \omega) \varphi_{k}$ belongs to the space $\mathbf{C}^{l}\left(\mathfrak{I} ; \mathbf{H}_{\mathbf{K}} \mathbf{L}_{2}\right)$, if the elements of the sequence of vectors $\left\{\eta_{k}\right\} \subset \mathbf{C}^{l} \mathbf{L}_{2}$ and all the Nelson - Gliklikh derivatives of these elements of the sequence up to the order $l \in\{0\} \cup \mathbb{N}$ inclusively are uniformly bounded with respect to the existing norm $\|\cdot\|_{\mathbf{C}^{l} \mathbf{L}_{2}}$.

Further, in the spaces of $\mathbf{K}$-"noises", we determine the coefficients of differential forms given on a manifold without boundary. Let $M_{d}$ be a smooth connected oriented compact 
Riemannian manifold without boundary of the class $C^{\infty}$ and of dimension $d$. On the manifold $M_{d}$, consider the vector space $E^{q}\left(M_{d}\right)$ of the $q$-forms

$$
a\left(x_{1}, \ldots, x_{n}\right)=\sum_{i_{1}<i_{2}<, \ldots,<i_{q}} a_{i_{1}, i_{2}, \ldots, i_{q}}\left(x_{1}, \ldots, x_{n}\right) d x_{i_{1}} \wedge d x_{i_{2}} \wedge \ldots \wedge d x_{i_{q}}
$$

where $a_{i_{1}, i_{2}, \ldots, i_{q}}\left(x_{1}, \ldots, x_{n}\right) \in C^{\infty}\left(M_{d}\right), q=\{0,1, \ldots, d\}$. On the space $E^{q}$, define the scalar product

$$
(a, b)_{0}=\int_{M_{d}} a \wedge * b,
$$

where $*$ is the Hodge operator that establishes a linear isomorphism of $q$-forms and $(p-q)$ forms on $M_{d}$, but (possible) up to a sign by virtue of $* *=(-1)^{q(p-q)}$. In the spaces $E^{q}$, the manifold $\left(M_{d}\right)$ is defined by the formula $\Delta=d \delta+\delta d$, where $d$ is the external differentiation operator, $\delta=(-1)^{n(k+1)+1} * d *$ is the Laplace - Beltrami operator. Introduce the following two scalar products:

$$
(a, b)_{1}=(a, b)_{0}+(\Delta a, b)_{0},(a, b)_{2}=(a, b)_{1}+(\Delta a, \Delta b)_{0} .
$$

Denote by $\mathbf{H}_{k}^{q}, k=0,1,2$ a Hilbert space obtained by completion of $E^{q}$ in the norm $\|\cdot\|_{k}$, induced by the scalar product $(\cdot, \cdot)_{k}, k=0,1,2, q \in\{0,1, \ldots, d\}$. The obtained separable Hilbert space $H_{k}^{q}$ has a basis of the eigenfunctions of the Laplace - Beltrami operator, be orthonormal with respect to the scalar product $(\cdot, \cdot)_{k}, k=0,1,2$..

Spaces of random $\mathbf{K}$-variables defined on the manifold $M_{d}$ : $\mathbf{U}_{\mathbf{K}} \mathbf{L}_{2}=\mathbf{H}_{0 \mathbf{K}}^{q} \mathbf{L}_{2}$ and $\mathbf{F}_{\mathbf{K}} \mathbf{L}_{2}=\mathbf{H}_{2 \mathbf{K}}^{q} \mathbf{L}_{2}$, where $\mathbf{K}=\left\{\lambda_{k}\right\}$ is a monotone sequence of eigenvalues of the Green operator (the eigenvalues are inverted to the eigenvalues of the Laplace - Beltrami operator). The elements of these spaces are the vectors $\alpha=\sum_{k=1}^{\infty} \lambda_{k} \xi_{k} \varphi_{k}$ and $\beta=\sum_{k=1}^{\infty} \lambda_{k} \xi \psi_{k}$, respectively, where $\left\{\varphi_{k}\right\}$ and $\left\{\psi_{k}\right\}$ are eigenvectors of the operator orthonormal with respect to $(\cdot, \cdot)_{0}$ and $(\cdot, \cdot)_{2}$.

Consider the spaces of $\mathbf{K}$-"noises" $\mathbf{C}^{l}\left(\mathfrak{I} ; \mathbf{H}_{0 \mathbf{K}}^{q} \mathbf{L}_{2}\right)$ and $\mathbf{C}^{l}\left(\left(\mathfrak{I} ; \mathbf{H}_{2 \mathbf{K}}^{q} \mathbf{L}_{2}\right), l \in\{0\} \cup \mathbb{N}\right.$, $q \in\{0,1, \ldots, d\}, \mathfrak{I} \subset \mathbb{R}$ is an interval.

\section{Solution of the Stochastic Variant of the Barenblatt - Zheltov - Kochina Equation on the Torus}

Consider the homogeneous Barenblatt - Zheltov - Kochina equation

$$
(\lambda-\Delta) u_{t}=\alpha \Delta u
$$

and the Cauchy problem

$$
u(0)=u_{0}
$$

We can [5], [7] to reduce (5), (6) to problem (1), (3). To this end, we define the operators

$$
L=(\lambda-\Delta)=(\lambda+d \delta+\delta d), M=\alpha \Delta=\alpha(d \delta+\delta d)
$$

and consider the stochastic equation

$$
L \stackrel{\circ}{\eta}=M \eta
$$


with the condition

$$
\eta(0)-\eta_{0}=0
$$

Theorem 3. [8] Let the operator $M$ be $(L, p)$-bounded, $p \in\{0\} \cup \mathbb{N}$. Then for any $\eta_{0} \in$ $\mathbf{U}_{\mathbf{K}} \mathbf{L}_{2}$ a.s. there exists the unique solution $\eta \in C^{1}\left(\mathfrak{I} ; \mathbf{U}_{\mathbf{K}} \mathbf{L}_{2}\right)$ to Cauchy problem (9) for equation (8) of the form $u(t)=U^{t} u_{0}$.

Let us consider the application of the obtained results to the Barenblatt - Zheltov Kochina equation in the spaces of $\mathbf{K}$-"noises defined on a smooth compact Riemannian oriented manifold without boundary. As such a manifold, we consider the two-dimensional torus $\mathbb{T}^{2}=[0,2 \pi] \times[0, \pi]$ and consider the stochastic variant of the Barenblatt - Zheltov - Kochina equation

$$
(\lambda+\Delta) u_{t}=\alpha \Delta u
$$

Define the operators $L$ and $M$ by the formulas

$$
L=(\lambda+d \delta+\delta d), M=\alpha(d \delta+\delta d) .
$$

For the two-dimensional torus with coordinates $x_{1}, x_{2}$, taking into account the general representation of the Laplace - Beltrami operator on the manifold $M_{d}$ with the Riemannian metric $g$

$$
\Delta_{M_{d}}=\frac{1}{\sqrt{|g|}}\left(\partial_{i} g^{i j} \partial_{j}\right)
$$

we obtain the Laplace - Beltrami operator in the form

$$
\Delta_{\mathbb{T}^{2}}=\left(8 \pi^{2} \partial_{x_{1}}^{2}-4 \pi \partial_{x_{1}} \partial_{x_{2}}+\partial_{x_{2}}^{2}\right) .
$$

The eigenvalues $\lambda_{k}$ are

$$
\lambda_{k}=\min _{E \subset \mathbb{Z}^{2},|E|=k+1} \max _{\left(c_{1}, c_{2}\right) \subset E} 4 \pi^{2}\left[c_{1}^{2}\left(1+\frac{2 \pi^{2}}{\pi^{2}}\right)-2 c_{1} c_{2} \frac{2 \pi}{\pi^{2}}+\frac{c_{2}^{2}}{\pi^{2}}\right] .
$$

Therefore, we have a non-negative, non-decreasing, finite multiple, converging only to $\infty$ sequence of eigenvalues $\left\{\lambda_{k}\right\}$, and the sequence of corresponding eigenfunctions $\left\{\varphi_{k}\right\}$ forms the necessary orthonormal basis in $\mathfrak{U}^{1}=\mathbf{H}_{0 \mathbf{K} \Delta}^{q \perp} \mathbf{L}_{2}$, where $\mathbf{H}_{0 \mathbf{K} \Delta}^{q \perp} \mathbf{L}_{2}$ is a subspace $\mathbf{H}_{0 \mathbf{K}}^{q} \mathbf{L}_{2}$ obtained by the Hodge - Kodair splitting [9], be orthogonal to harmonic forms for $\lambda \neq \lambda_{k}$.

Since the dimension of the manifold is $d=2$, we have solutions of two types. The first type takes place for 0 -forms (and 2-forms isomorphic to them), and the second type takes place for 1 -forms.

The relative spectrum of the Barenblatt - Zheltov - Kochina equation has the form

$$
\sigma^{L}(M)=\left\{\mu_{k}=\frac{\alpha}{\lambda-\lambda_{k}}\right\}
$$

therefore, the operator $M$ is $(L, p)$-bounded. For the inhomogeneous Barenblatt - Zheltov - Kochina equation

$$
L \stackrel{\circ}{\eta}=M \eta+f
$$

it is necessary to find the projections of the inhomogeneity $f$ onto the corresponding subspaces by the existing projectors $Q,(I-Q)$, see Theorem 2 . 


\section{The Numerical Solution of the Stochastic Barenblatt - Zheltov - Kochina Equation on the Torus}

Numerical solution of the Cauchy problem for the Barenblatt - Zheltov - Kochina equation was carried out in Maple using the operators and variables implemented in Maple. The solution algorithm is presented by the block diagram given in Fig. 1. The numerical

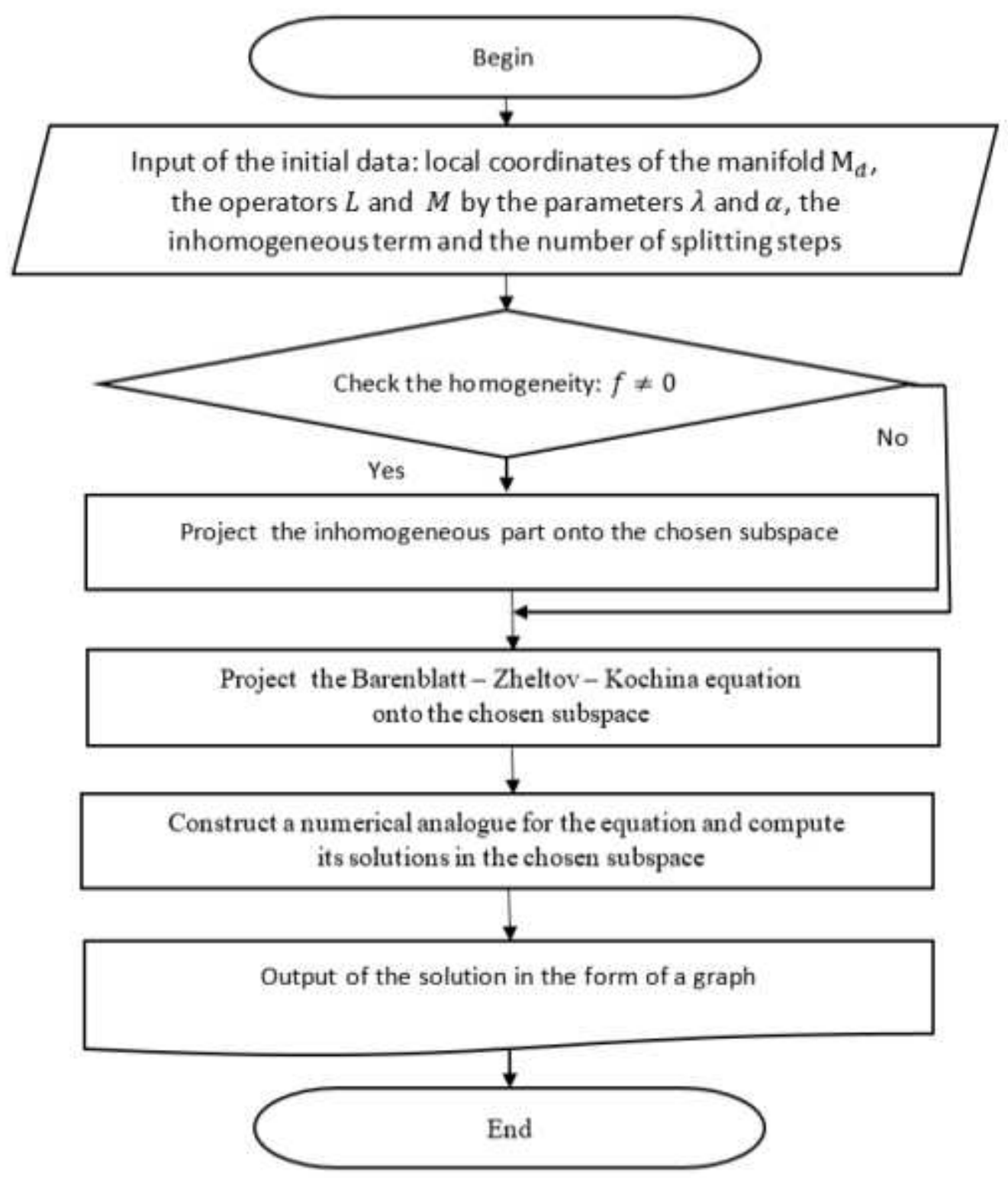

Fig. 1. Block diagram of the algorithm

solution was obtained with the given step up to the time $T=4$. An approximate solution is obtained by approximating the first three basic functions of the Galerkin method in the form of product of expansions in cosines of the trigonometric system in the variable $x$ and in sines of the trigonometric system in the variable $y$. Random values are introduced using the randomize procedure. The initial condition is expanded in a series in the eigenvalues of the Green operator for the Laplace equation, which are inverse with respect to the 
eigenvalues of the Laplace operator. The graphs show the solutions at the time instants $t_{k}, k=1, \ldots, 8$, by the corresponding colors: green, red, orange, gold, yellow, blue, violet, black (see Fig. 2).

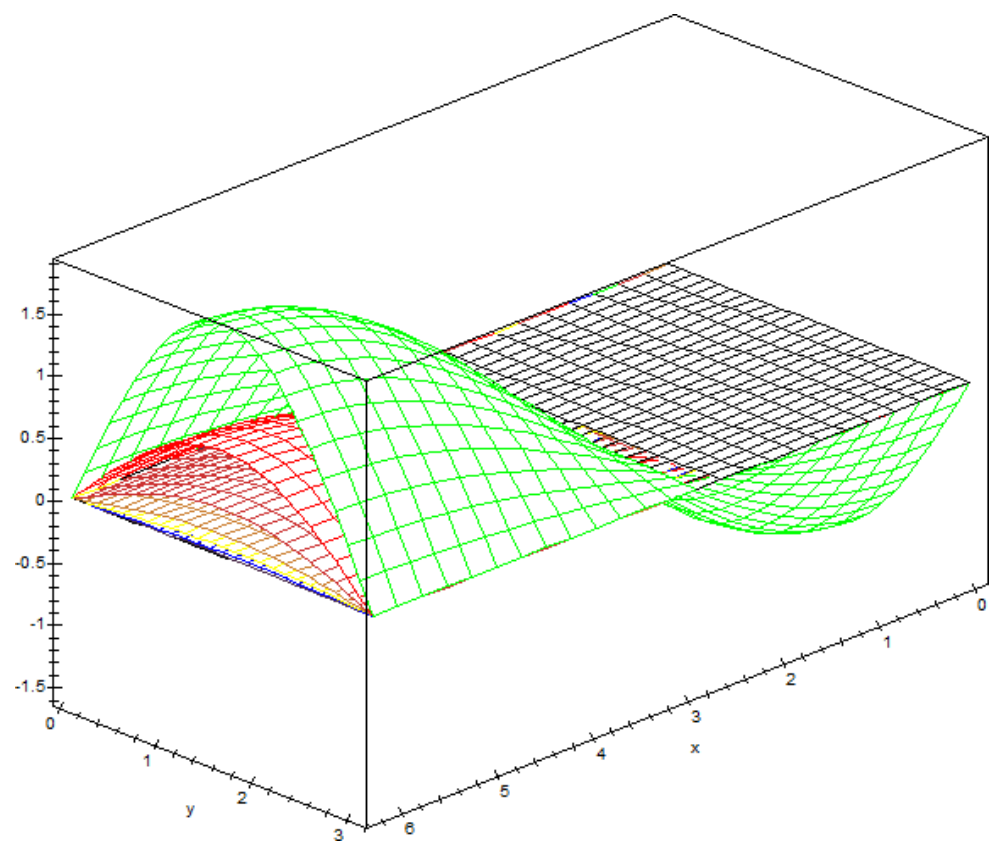

Fig. 2. The graph of the solution with $\lambda=2, \alpha=1, f=0$

Fig. 2 shows the graphs of the solution in the first eight time cutoffs of the homogeneous Cauchy problem with $\lambda=2, \alpha=1$. Fig. 3 shows the graphs of the solution in the first eight time cutoffs of the homogeneous Cauchy problem with $\lambda=-2.5, \alpha=0.5$.

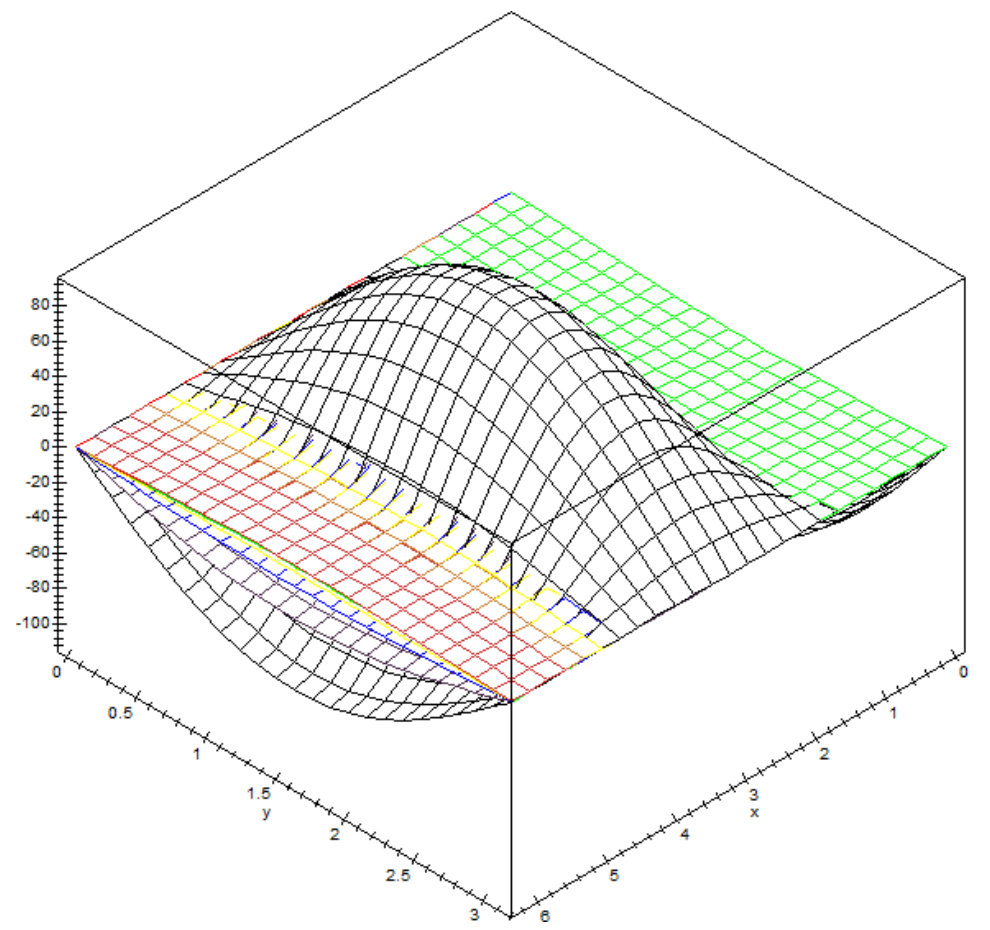

Fig. 3. The graph of the solution with $\lambda=-2.5, \alpha=0.5, f=0$ 
Further, we present a graph of the solution with $\lambda=7, \alpha=0.5$ for a homogeneous equation and inhomogeneous equation with $f=5 \sin (t)$ in Fig. 4 and in Fig. 5, respectively.

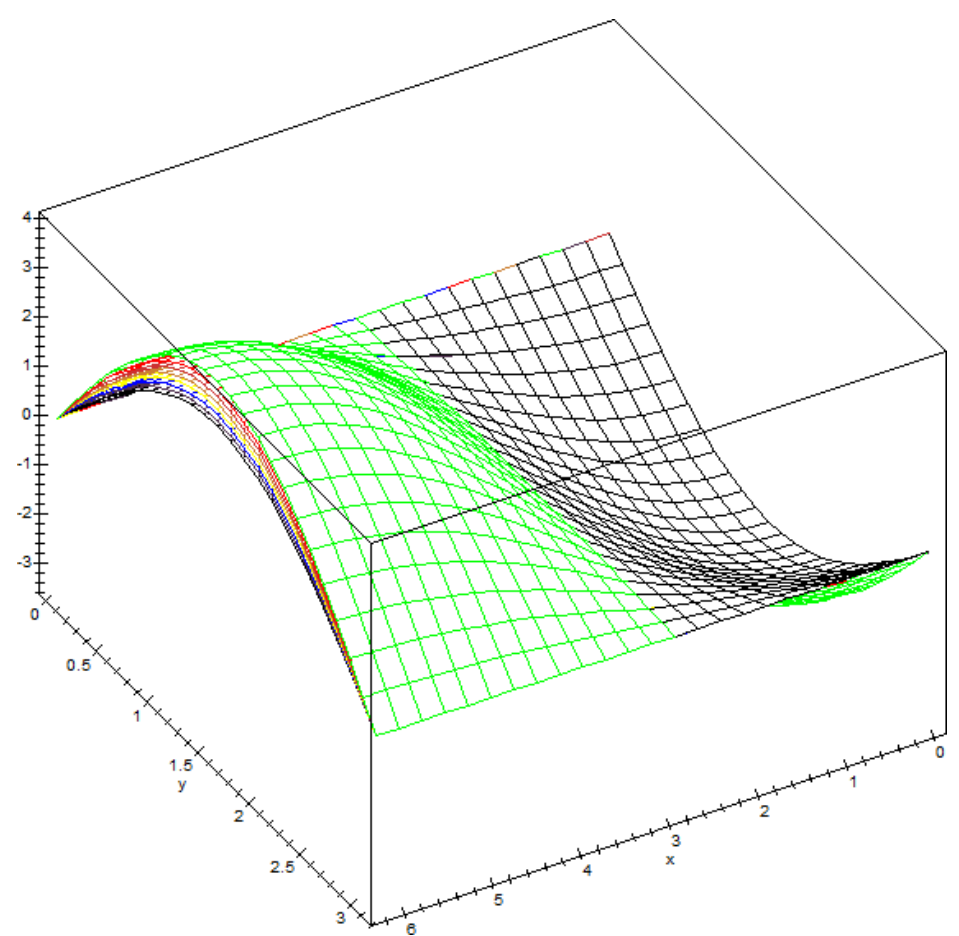

Fig. 4. The graph of the solution with $\lambda=7, \alpha=0.5, f=0$

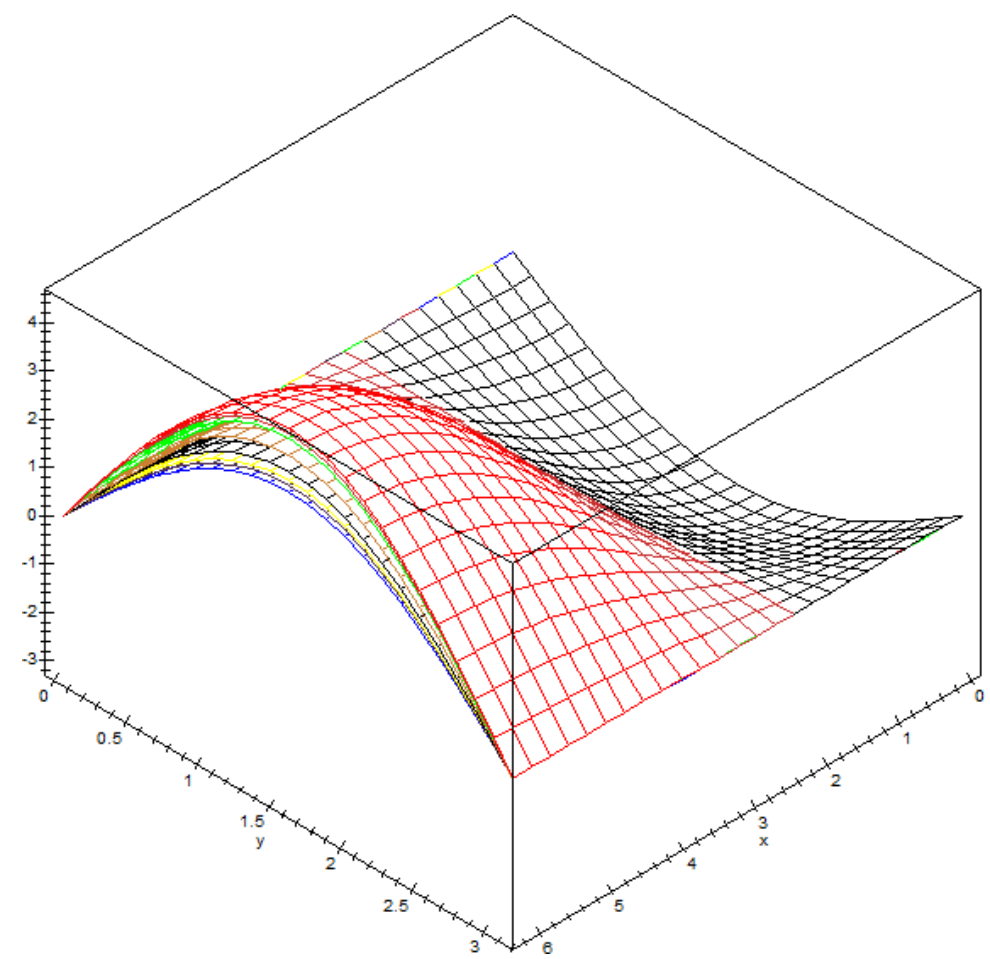

Fig. 5. The graph of the solution with $\lambda=7, \alpha=0.5, f=5 \sin (t)$ 


\section{References}

1. Barenblatt G. I., Zheltov Yu. P., Kochina I. N. Basic Concepts in the Theory of Seepage of Homogeneous Fluids in Fissurized Rocks. Journal of Applied Mathematics and Mechanics, 1960, vol. 24, no. 5, pp. 1286-1303.

2. Hallaire M. Soil Water Movement in the Film and Vapor Phase Under the Influence of Evapotranspiration. Water and Its Conduction Insoils. Proceedings of XXXVII Annual Meeting of the Highway Research Board, Highway Research Board Special Report, 1958, vol. 40 , pp. 88-105.

3. Chen P. J., Gurtin M. E. On a Theory of Heat Conduction Involving Two Temperatures. Journal of Applied Mathematics and Physics (ZAMP), 1968, vol. 19, no. 4, pp. 614-627.

4. Sviridyuk G. A. On the General Theory of Operator Semigroups. Russian Mathematical Surveys, 1994, vol. 49, no. 4, pp. 47-74. DOI: $10.1070 /$ RM1994v049n04ABEH002390

5. Shafranov D. E., Shvedchikova A. I. The Hoff Equation as a Model of Elastic Shell. Bulletin of the South Ural State University. Series: Mathematical Modelling, Programming and Computer Software, 2012, no. 18 (277), issue 12, pp. 77-81. (in Russian)

6. Shafranov D. E. The Splitting of the Domain of the Definition of the Elliptic Self-Adjoint Pseudodifferential Operator. Journal of Computation and Engineering Mathematics, 2015, vol. 2, no. 3, pp. 60-64. DOI: 10.14529/jcem150306.

7. Shafranov D. E., Kitaeva O. G. The Barenblatt - Zheltov - Kochina Model with the Showalter - Sidorov Condition and Additive "White Noise" in Spaces of Differential Forms on Riemannian Manifolds without Boundary. Global and Stochastic Analysis, 2018, vol. 5, no. 2, pp. 145-159.

8. Kitaeva O. G., Shafranov D. E., Sviridyuk G. A. Exponential Dichotomies in Barenblatt-Zheltov-Kochina Model in Spaces of Differential Forms with "Noise". Bulletin of the South Ural State University. Series: Mathematical Modelling, Programming and Computer Software, 2019, vol. 12, no. 2, pp. 47-57. DOI: $10.14529 / \mathrm{mmp} 190204$

9. Warner F. Foundations of Differentiable Manifolds and Lie Groups. N.Y., SpringerVerlag., 1983, 276 p.

10. Gliklikh Yu. E. Global and Stochastic Analysis with Applications to Mathematical Physics. London, Dordrecht, Heidelberg, N.Y., Springer, 2011, 436 p. DOI: $10.1007 / 978-0-85729-163-9$

11. Sviridyuk G. A., Manakova N. A. The Dynamical Models of Sobolev Type with Showalter-Sidorov Condition and Additive "Noise". Bulletin of the South Ural State University. Springer, 2014, vol. 7, no. 1, pp. 90-103. DOI: 10.14529/mmp140108

12. Favini A., Sviridyuk G. A., Zamyshlyaeva A. A. One Class of Sobolev Type Equations of Higher Order with Additive "White Noise". Communications on Pure and Applied Analysis, 2016, vol. 15, no. 1, pp. 185-196. DOI: 10.3934/cpaa.2016.15.185 
13. Favini A., Sviridyuk G. A., Sagadeeva M. A. Linear Sobolev Type Equations with Relatively $p$-Radial Operators in Space of "Noises". Mediterranean Journal of Mathematics, 2016, vol. 13. no. 6, pp. 4607-4621. DOI: 10.1007/s00009-016-0765-x

14. Zagrebina S. A., Soldatova E. A., Sviridyuk G. A. The Stochastic Linear Oskolkov Model of the Oil Transportation by the Pipeline. Springer Proceedings in Mathematics and Statistics, 2015, vol. 113, pp. 317-325. DOI: 978-3-319-12145-1_20

15. Shestakov A. L., Sviridyuk G. A. On a New Conception of White Noise. Obozrenie Prikladnoy $i$ Promyshlennoy Matematiki, 2012, vol. 19, issue 2, pp. 287-288. (in Russian).

16. Shestakov A. L., Sviridyuk G. A., Chudyakov Yu. V. Dinamic Measurement in Spaces of "Noise". Bulletin of the South Ural State University. Series: Computer Technologies, Automatic Control, Radio Electronics, 2013, vol. 13, no. 2, pp. 4-11. (in Russian).

17. Sviridyuk G. A., Brychev S. V. Numerical Solution of Systems of Equations of Leontevs Type. Russian Mathematics (Iz. VUZ), 2003, vol. 47, no. 8, pp. 44-50.

Dmitry E. Shafranov, PhD (Math), Associate Professor, Department of Mathematical Physic Equations, South Ural State University (Chelyabinsk, Russian Federation), shafranovde@susu.ru.

Received August 27, 2019

УДК 517.9

DOI: $10.14529 /$ jcem 190403

\title{
ЧИСЛЕННОЕ РЕШЕНИЕ УРАВНЕНИЯ БАРЕНБЛАТТА - ЖЕЛТОВА - КОЧИНОЙ С АДДИТИВНЫМ "БЕЛЫМ ШУМОМ" В ПРОСТРАНСТВАХ ДИФФЕРЕНЦИАЛЬНЫХ ФOPM HA TOPE
}

\section{Д. Е. Шафранов}

\begin{abstract}
Работа посвящена поиску численных решений задачи Коши для линейного стохастического уравнения Баренблатта - Желтова - Кочиной в пространстве гладких дифференциальных форм на торе. Исходя из ранее полученных результатов по виду аналитического решения стохастическог варианта уравнения Баренблатта - Желтова Кочиной в пространствах гладких дифференциальных форм на гладких компактных римановых многоообразиях без края и выбирая из аналитического решения несколько слагаемых, строятся графики численного решения для различных значений коэффициентов и неоднородного члена. Это уравнения относится к уравнениям соболевского типа с вырожденным оператором при производной, что и позволило решить различные начально-краевые задачи с помощью теории вырожденных аналитических групп и полугрупп разрешающих операторов. В детерминированном случае решение строится на фазовом подпространстве исходного пространства. В пространствах дифференциальных форм используется инвариантная форма лапласиана - оператор Лапласа Бельтрами. Метод фазового пространства используется и в недетерминированном
\end{abstract}


случае, но, в силу недифференцируемости "белого шума" в обычном понимании, мы используем производную Нельсона - Гликлиха. Двумерный тор в нашей статье играет роль гладкого компактного ориентированного риманового многообразия без края. Численные решения находятся при помощи метода Галеркина и представлены для нескольких фиксированных моментов времени, как графики коэффициентов дифференциальных форм, полученных в системе Maple.

Ключевые слова: уравнения соболевского типа; производная Нельсона - Гликлиха; оператор Лапласа - Бельтрами.

\section{Литература}

1. Баренблатт, Г. И. Об основных представлениях в теории фильтрации жидкости в трещиновато-пористых средах / Г. И. Баренблатт, Ю. П. Желтов, И. Н. Кочина // Прикладная математика и механика. - 1960. - Т. 24, № 5. - С. 852-864.

2. Hallaire, M. Soil Water Movement in the Film and Vapor Phase Under the Influence of Evapotranspiration. Water and Its Conduction Insoils / M. Hallaire // Proceedings of XXXVII Annual Meeting of the Highway Research Board, Highway Research Board Special Report - 1958. - T. 40. - P. 88-105.

3. Chen, P. J. On a Theory of Heat Conduction Involving Two Temperatures / P. J. Chen, M. E. Gurtin // Journal of Applied Mathematics and Physics (ZAMP). - 1968. - V. 19, № 4. - P. 614-627.

4. Свиридюк, Г. А. К общей теории полугрупп операторов / Г. А. Свиридюк Успехи математических наук. - 1994. - V. 49, № 4. - С. 47-74.

5. Шафранов, Д. Е. Уравнение Хоффа как модель упругой оболочки / Д. Е. Шафранов, А. И. Шведчикова / Вестник ЮУрГУ. Серия: Математическое моделирование и программирование. - 2012. - № 2. - С. 77-81.

6. Shafranov, D. E. The Splitting of the Domain of the Definition of the Elliptic Selfadjoint Pseudodifferential Operator / D. E. Shafranov // Journal of Computation and Engineering Mathematics. - 2015. - V. 2, № 3. - P. 60-64.

7. Shafranov, D. E. The Barenblatt - Zheltov - Kochina Model with the Showalter Sidorov Condition and Additive "White Noise" in Spaces of Differential Forms on Riemannian Manifolds without Boundary / D. E. Shafranov, O. G. Kitaeva // Global and Stochastic Analysis. - 2018. - V. 5, № 2. - P. 145-159.

8. Kitaeva, O. G. Exponential Dichotomies in Barenblatt - Zheltov - Kochina Model in Spaces of Differential Forms with "Noise" / O. G. Kitaeva, D. E. Shafranov, G. A. Sviridyuk / Вестник ЮУрГУ. Серия: Математическое моделирование и программирование. - 2019. - Т. 12, № 2. - С. 47-57.

9. Уорнер, Ф. Основы теории гладких многообразий и групп Ли / Ф. Уорнер. - М.: Мир, 1987. - 302 с.

10. Gliklikh, Yu. E. Global and Stochastic Analysis with Applications to Mathematical Physics / Yu. E. Gliklikh. - London, Dordrecht, Heidelberg, N.Y.: Springer, 2011. $436 \mathrm{p}$. 
11. Sviridyuk, G. A. The Dynamical Models of Sobolev Type with Showalter-Sidorov Condition and Additive "Noise" / G. A. Sviridyuk, N. A. Manakova // Вестник ЮУрГУ. Серия: Математическое моделирование и программирование. - 2014. T. 7, № 1. - C. 90-103.

12. Favini, A. One Class of Sobolev Type Equations of Higher Order with Additive "White Noise" / A. Favini, G. A. Sviridyuk, A. A. Zamyshlyaeva // Communications on Pure and Applied Analysis. - 2016. - V. 15, № 1. - P. 185-196.

13. Favini, A. Linear Sobolev Type Equations with Relatively $p$-Radial Operators in Space of "Noises" / A. Favini, G. A. Sviridyuk, M. A. Sagadeeva // Mediterranean Journal of Mathematics. - 2016. - V. 13, № 6. - P. 4607-4621.

14. Zagrebina, S. A. The Stochastic Linear Oskolkov Model of the Oil Transportation by the Pipeline / S. A. Zagrebina, E. A. Soldatova, G. A. Sviridyuk // Springer Proceedings in Mathematics and Statistics. - 2015. - V. 113. - P. 317-325.

15. Шестаков, А. Л. О новой концепции в белого шума / А. Л. Шестаков, Г. А. Свиридюк // Обозрение прикладной и промышленной математики. - 2012. - Т. 19, № 2. - C. 287-288.

16. Шестаков, А. Л. Динамические измерения в пространствах "шумов" / А. Л. Шестаков, Г. А. Свиридюк, Ю. В. Худяков // Вестник ЮУрГУ. Серия: Компьютерные технологии, управление и радиоэлектроника. - 2013. - Т. 13, № 2. - С. 4-11.

17. Свиридюк, Г. А. Численное решение систем уравнений леонтьевского типа / Г. А. Свиридюк, С. В. Брычев // Известия вузов. Математика. - 2003. - № 8. C. $46-52$

Шафранов Дмитрий Евгенъевич, кандидат физико-математических наук, дочент, доцент кафедры уравнений математической физики, ЮжноУральский государственный университет (г. Челябинск, Российская Федерачия), shafranovde@susu.ru.

Поступила в редакиию 27 августа 2019 г. 